\title{
EFEITO DE CULTIVAR E DO DESPENDOAMENTO NA PRODUÇÃO DE MINIMILHO
}

\author{
Heros Targanski ${ }^{1}$, Claudio Yuji Tsutsumi ${ }^{2}$
}

\begin{abstract}
RESUMO - O milho é uma cultura amplamente disseminada e utilizada de várias formas para alimentação humana e animal, e com usos na indústria. Uma possibilidade de utilização do milho que se mostra promissora é a produção de minimilho, porém ainda são escassas informações sobre o manejo e sobre cultivares adequadas para esta especialidade. Com o objetivo de avaliar o desempenho de cultivares de milho, e suas respostas a prática do despendoamento para a produção de minimilho foi realizado experimento de campo em Marechal Cândido Rondon - PR. As cultivares avaliadas foram: Al34, BM3061, Cativerde 02 e Pioneer 30S40. Os parâmetros avaliados foram número de espigas, comprimento, diâmetro e massa de espigas com palha e descascadas, número de espigas comerciais, produtividade em $\mathrm{kg} \mathrm{ha}^{-1}$ de espigas comerciais com e sem palha, relação entre número de espigas comerciais e número total de espigas, e relação entre massa de espiga sem palha e massa de espiga com palha. As cultivares Pioneer 30 S40 e BM3061 mostraram-se mais produtivas no número total de espigas e na produtividade de Massa de espigas comerciais sem palha. O despendoamento afetou a produção de espigas com palha, porém não proporcionou ganho na massa de espigas sem palha.
\end{abstract}

Palavras chave: adubação nitrogenada, bactérias diazotróficas, inoculante, Zea mays L.

\section{EFFECT OF CULTIVAR AND DETASSELING ON THE PRODUCTION OF BABY CORN}

\begin{abstract}
Corn is a widely disseminated and widely used crop for food and feed, and uses in industry. One possibility of maize utilization that is promising is the production of baby corn, but there is still scarce information on the management and on suitable cultivars for this specialty. A field experiment was carried out in Marechal Cândido Rondon - PR, Brazil, in order to evaluate the performance of maize cultivars and their responses to the practice of detasseling in the production of baby corn. The evaluated cultivars were: Al34, BM3061, Cativerde 02 and Pioneer 30S40. The parameters evaluated were number of ears, length, diameter and mass of ears no husked and husked, number of commercial ears, relation between productivity, in $\mathrm{kg} \mathrm{ha}^{-1}$, of commercial ears with and without straw, relation between number of commercial ears and total number of ears, and the relationship between husked ears mass and ears mass with straw. The cultivars Pioneer $30 S 40$ and BM3061 showed to be more productive in the total number of ears and in the yield of commercial ears mass without straw. Detasseling affected the production of ears with straw, but did not provide gain in the mass of ears without straw.
\end{abstract}

Keywords: cultivars, ears, productivity, tassel, Zea mays.

\footnotetext{
${ }^{1}$ Professor EBTT (Agronomia), Mestre, Instituto Federal de Educação Ciência e Tecnologia de Rondônia - IFRO, RO-257, s/n - Zona Rural, 76870-000, Ariquemes - RO, Brasil. heros.targanski@ifro.edu.br

${ }^{2}$ Professor (Agronomia), Doutor, Universidade Estadual do Oeste do Paraná - Unioeste, Rua Pernambuco, 1777 - Centro, 85960-000, Marechal Cândido Rondon - PR, Brasil. claudio.tsutsumi@unioeste.br
} 


\section{INTRODUÇÃO}

O milho possui diversos usos, e uma alternativa é a produção de minimilho. O qual é a inflorescência feminina colhida após a emissão dos estilo-estigmas.

Lima et al. (2015) analisaram a composição de minimilho de seis variedades (Pipoca, Super Doce, Doce Cristal, Eldorado, Catetinho e Branco) produzidas em sistema orgânico em Seropédica/RJ; obtiveram valores de teores de umidade de 83,02 a 92,10\%; cinzas de 0,32 a 0,70\%; lipídeos de 0,83 a 1,14\%; proteínas de 0,41 a $0,51 \%$ e carboidratos de 6,07 a $13,84 \%$. As autoras concluíram que o minimilho tem a vantagem de ser uma hortaliça de baixo valor calórico.

Outra vantagem da produção de minimilho é a possibilidade de utilização das plantas (remanescentes da produção de minimilho) após a colheita das inflorescências. Arcanjo Junior et al. (2016) analisando remanescentes de plantas de milho da produção de minimilho de um híbrido (AG1051) e quatro cultivares de polinização aberta, em Garanhuns-PB, obtiveram percentuais de matéria seca entre 19,6 e 21,8\%, proteína bruta entre 6,29 e 6,98\% e nutrientes digestíveis totais entre 60 e 62,5\%, com percentuais médios de matéria seca, de proteína bruta e de nutrientes digestíveis totais de 20,95, 6,61 e 61,3, respectivamente. Segundo os autores, do ponto de vista nutricional, as plantas remanescentes após a colheita de minimilho, assim como as plantas inteiras (plantas com espigas), podem ser utilizadas para a alimentação de ruminantes.

Do ponto de vista econômico Silva et al. (2006) avaliaram a rentabilidade da produção de milho verde e de milho em grão após a colheita da primeira espiga como minimilho e chegaram a conclusão que os melhores ganhos são obtidos com a produção de milho verde, minimilho e posterior colheita de milho verde, apenas minimilho, minimilho e posterior colheita de grãos, e por último a colheita do milho em grãos. Com as informações destes autores observa-se que a produção de minimilho é uma alternativa rentável para o produtor rural.

O melhoramento genético do milho tem como foco o desenvolvimento de cultivares para a produção de grãos e para silagem. Quanto à produção de minimilho têm sido testados híbridos e variedades de milho, pipoca e milho doce. Moreira et al. (2014) testaram os seguintes materiais para a produção de minimilho em campo Mourão
- PR: Milho Híbrido Simples ATL 200, Milho Doce BonaVerde, Milho Canjica AL Branco, Milho Pipoca Híbrido Itapuã 900 e o Milho Super-Doce (HAVAI). As autoras encontraram diferenças de comportamento entre os materiais testados, indicando a possibilidade seleção de cultivares com desempenho superior para a produção de minimilho. Melo et al. (2014) testaram a aceitação de conservas orgânicas de minimilho de seis genótipos distintos e constataram pela realização de análise sensorial que os materiais diferem quanto a aceitação pelos consumidores. Isso indica que a seleção de cultivares para a produção de minimilho não deve levar em conta apenas atributos de produtividade, mas também a aceitabilidade.

Quanto ao manejo e tratos culturais, a pesquisa tem buscado aprimorar o conhecimento sobre a irrigação, adubação, e sobre a prática do despendoamento das plantas para a produção de minimilho. Pereira filho et al. (2009) avaliou seis genótipos de milho, em três épocas de plantio, com realização do despendoamento e sem a prática do despendoamento; constataram incremento de produtividade e rendimento para alguns tratamentos nos quais foi realizada a remoção do pendão. Porém em alguns tratamentos com remoção do pendão o resultado foi o inverso, indicando a necessidade de novas pesquisas para definir se o despendoamento é uma prática compensadora, e em quais genótipos é aconselhável a realização do despendoamento.

Tendo em vista a escassez de informação sobre as práticas que contribuem para produtividade e qualidade do minimilho, bem como a carência de cultivares selecionadas especialmente para sua produção, objetivouse com este trabalho avaliar quatro cultivares de milho e o efeito do despendoamento na produtividade de minimilho.

A hipótese levantada para a realização da pesquisa é que as cultivares possuem diferentes desempenhos para produção de minimilho, e o despendomento proporciona aumento de rendimento de minimilho, porque sem este órgão a planta terá um dreno a menos para nutrir (pendão), podendo assim direcionar mais energia para a formação de inflorescências femininas (minimilho).

\section{MATERIALE MÉTODOS}

A pesquisa foi conduzida na Fazenda Experimental Antônio dos Santos Pessoa, pertencente ao Núcleo de Estações Experimentais da Universidade Estadual 
do Oeste do Paraná, Campus de Marechal Cândido Rondon, situada a $24^{\circ} 33^{\prime} 40^{\prime \prime}$ Latitude Sul e 54 $04^{\circ}$ ' 12 "' longitude Oeste numa altitude de $420 \mathrm{~m}$.

O material genético utilizado no experimento compreendeu quatro cultivares de milho: CATI AL 34 (variedade de polinização aberta), CATI Cativerde 02 (variedade de polinização aberta), Biomatrix BM 3061 (híbrido triplo) e Pioneer 30 S40 (híbrido simples).

Foi utilizado o delineamento experimental em blocos casualizados num esquema fatorial 4 (cultivares) x 2 (despendoamento) com 3 repetições, totalizando 24 parcelas experimentais. Cada parcela contou de 4 linhas com $3 \mathrm{~m}$ de comprimento com espaçamento de $0,70 \mathrm{~m}$ entre linhas. Foram avaliados $2 \mathrm{~m}$ de uma das linhas centrais. $\mathrm{O}$ espaçamento entre linhas foi de $0,70 \mathrm{~m}$.

A divisão das parcelas foi realizada no dia 20 de março de 2010, sendo, então, realizadas as operações de estaqueamento e semeadura das cultivares de milho.

No plantio foi aplicado no sulco de plantio 270 $\mathrm{kg} \mathrm{h}^{-1}$ de fertilizante N-P-K na formulação 8-15-15.

A demarcação das linhas de plantio e a aplicação do fertilizante foi feita com plantadeira, e o plantio foi manual, sendo colocadas 5 a 6 sementes por cova, sendo estas espaçadas em $25 \mathrm{~cm}$, após a emergência das plantas foi feito o desbaste, deixando-se apenas 4 plantas por cova.

O despendoamento foi sendo realizado conforme as plantas foram emitindo os pendões, sendo que este iniciou-se no final de maio e terminou no inicio de junho. O despendoamento foi realizado manualmente, puxandose o pendão para fora logo quando este estava começando a emergir do "cartucho".

O ponto de colheita das espigas era quando os estilo-estigma estavam com aproximadamente 2 a $3 \mathrm{~cm}$ de comprimento.

A colheita foi realizada manualmente, sendo iniciada no dia 11 de junho e concluída no dia 05 de julho de 2010.

Após a colheita as espigas foram levadas ao Laboratório de Física do Solo, da Universidade Estadual do Oeste do Paraná, Campus de Marechal Cândido Rondon, para serem pesadas, descascadas e mensuradas.

Foram avaliados os seguintes parâmetros:

a) Comprimento de espiga com palha (CCP): medida diretamente utilizando-se uma régua, em cm; b) Comprimento de espiga sem palha (CSP): obtido diretamente por meio de medição com régua, em cm;

c) Diâmetro de espiga com palha (DCP): medido diretamente por meio de paquímetro, em $\mathrm{cm}$;

d) Diâmetro de espiga sem palha (DSP): obtido por mensuração direta através de paquímetro, em cm;

e) Massa de espiga com palha (MCP): obtida por meio de balança digital, em g;

f) Massa de espiga sem palha (MSP): medida diretamente por meio de balança digital, em g;

g) Número total de espigas (NESP): obtido da soma das produções das colheitas na parcela, sendo o número extrapolado para 1 hectare;

h) Número de espigas comerciais (NCESP): obtido da soma das produções das colheitas em cada parcela, sendo consideradas aquelas espigas que possuíam comprimento de espiga sem palha entre 4 e $12 \mathrm{~cm}$ e diâmetro entre 0,8 e 1,8 cm; o valor encontrado foi extrapolado para 1 hectare;

i) Produtividade de espigas comerciais sem palha (MTSP): obtida da soma da produção de espigas sem palha em cada parcela, transformado em $\mathrm{kg} \mathrm{ha}^{-1}$;

j) Produtividade comercial com palha (MTCP): obtida da soma da produção de espigas comerciais com palha em cada parcela, transformado em $\mathrm{kg} \mathrm{ha}^{-1}$;

k) NC/NT: relação entre o número total de espigas comerciais e o número total de espigas;

1) SP/CP: relação entre a massa de espigas comerciais sem palha e a massa de espigas com palha.

Efetuou-se a análise de variância (ANOVA), sendo o sistema utilizado o SAEG (Sistema Estatístico-Genético da UFV), para cada caráter avaliado. As médias foram comparadas pelo teste de Tukey, quando o valor de F foi significativo ao nível 1\% de probabilidade.

\section{RESULTADOS E DISCUSSÃO}

Os quadrados médios e os coeficientes de variação da análise de variância das quatro cultivares de milho submetidas e não submetidas ao despendoamento são apresentados na Tabela 1. Foram encontradas diferenças entre as cultivares ao nível de $1 \%$ para todos os parâmetros avaliados, exceto para o comprimento de espiga sem palha (CSP). 
Em relação aos tratamentos com e sem despendoamento foram encontradas diferenças ao nível de $1 \%$ para Massa de espiga com palha (MCP), Comprimento da espiga com palha (CCP), Massa de espiga sem palha (MSP), Número total de espigas (NTESP), Massa total de espigas comerciais com palha (MTCP) e Relação entre massa total de espigas comerciais sem palha e massa de espigas comerciais com palha

Tabela 1 - Quadrados médios e coeficiente de variação da análise de variância de quatro cultivares de milho submetidas ou não ao despendoamento em Marechal Cândido Rondon - PR - 2010

\begin{tabular}{lrrrr}
\hline \multirow{2}{*}{ Fontes de variação } & GL & \multicolumn{3}{c}{ Quadrados médios } \\
\cline { 3 - 5 } & & MCP & CCP & DCP \\
\hline Bloco & 2 & 627,24 & 39,01 & 0,321 \\
Cultivar & 3 & $1753,41 * * *$ & $192,59 * *$ & 1,970 \\
Despendoamento & 1 & $1135,39 * *$ & $149,77 * *$ & 0,242 \\
Cv x Desp & 3 & 222,30 & 8,60 & 0,244 \\
Erro & 628 & 627,24 & 9,88 & 0,123 \\
CV(\%) & & 44,62 & 19,13 & 16,47 \\
Média & & 30,31 & 16,42 & 2,13 \\
\end{tabular}

\begin{tabular}{|c|c|c|c|c|c|c|}
\hline \multirow{2}{*}{ Fontes de variação } & \multirow{2}{*}{ GL } & \multicolumn{4}{|c|}{ Quadrados médios } & \\
\hline & & MSP & & CSP & DSP & \\
\hline Bloco & 2 & 5,29 & & 1,82 & 0,0481 & \\
\hline Cultivar & 3 & 57,49 & $*$ & 4,40 & 0,3996 & ** \\
\hline Despendoamento & 1 & 25,40 & $*$ & 0,54 & 0,1986 & \\
\hline Cv x Desp & 3 & 37,71 & $*$ & 3,83 & 0,1789 & ** \\
\hline Erro & 628 & 11,51 & & 2,20 & 0,0591 & \\
\hline CV(\%) & & 44,04 & & 19,32 & 17,01 & \\
\hline Média & & 7,70 & & 7,68 & 1,42 & \\
\hline
\end{tabular}

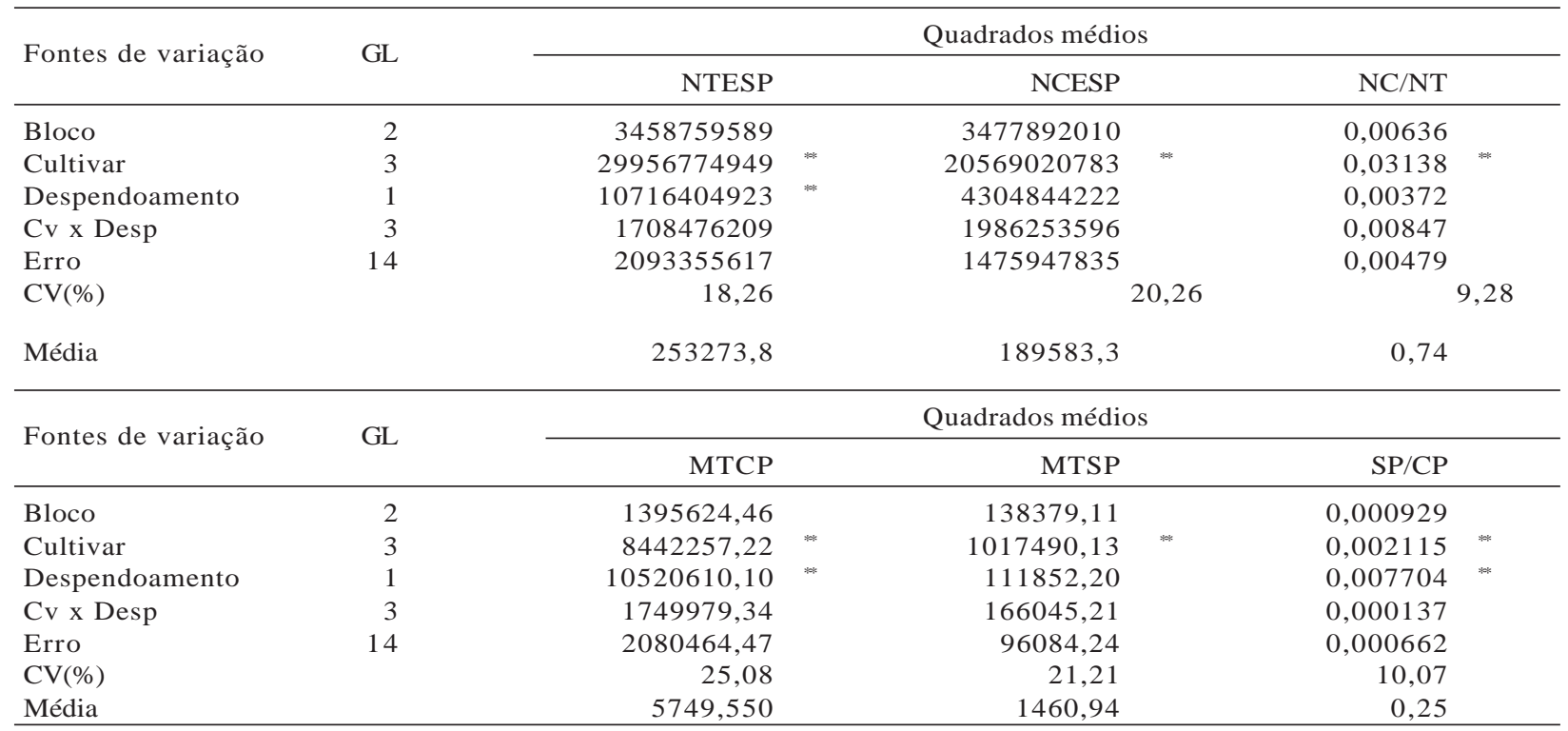

Massa de espiga com palha (MCP), em g; Comprimento da espiga com palha (CCP), em cm; Diâmetro da espiga com palha (DCP), em cm; Massa de espiga sem palha (MSP), em g; Comprimento da espiga sem palha (CSP), em cm; Diâmetro da espiga sem palha (DSP), em cm; Número total de espigas colhidas (NTESP), em espigas ha ${ }^{-1}$; Número de espigas comerciais (NCESP), em espigas ha ${ }^{-1}$; relação número de espigas comerciais por número total de espigas (NC/NT); Massa total de espigas comerciais com palha (MTCP), em kg ha${ }^{1}$; Massa total de espigas comerciais sem palha (MTSP), em kg ha ${ }^{-1}$; relação massa de espigas comerciais sem palha por massa de espigas comerciais com palha (SP/CP).

**, *: Significativo a 1 e $5 \%$ de probabilidade pelo teste $\mathrm{F}$. 
(SP/CP). Foram encontradas interações significativas entre as cultivares avaliadas e a prática do despendoamento apenas para Massa de espiga sem palha (MSP) e para Diâmetro de espiga sem palha (DSP).

Os valores médios de Massa de espiga com palha (MCP) são apresentados na Tabela 2. Não houve efeito de interação entre cultivares e o despendoamento, porém houve diferença estatística entre as plantas com pendão e as despendoadas, sendo que as espigas das plantas que foram despendoadas apresentaram maior valor médio de massa de espiga com palha, sendo de 32,35 gramas; já o valor médio de massa de espiga com palha das espigas oriundas das plantas que não foram despendoadas foi de 29,85 g.

Para a massa de espigas com palha a cultivar Pioneer 30S40, com média de 26,5 g, diferiu das demais apresentando o menor valor médio de massa de espiga com palha, as outras cultivares avaliadas não diferiram entre si; as médias de massa de espiga com palha para as cultivares AL34, BM3061 e Cativerde 02, foram de 32,27 g, 31,64 g e 33,98 g, respectivamente. Estes valores foram menores do que as médias obtidas por Raupp et al. (2008), que avaliando 4 cultivares hibridas para a produção de minimilho obtiveram valores entre 39,6 g e 42,7 g, porém sem encontrar diferença estatística entre as cultivares avaliadas (DKB 214, P 3021, AG 6018 e DKB 215).

A Tabela 3 mostra os valores médios de comprimento de espiga com palha (CCP) para as quatro cultivares avaliadas em função do despendoamento. A cultivar Pioneer 30 S40 diferiu das outras, apresentando o menor valor médio de comprimento de espiga com palha, 15,13 cm. Wangen \& Faria (2013) avaliaram cinco genótipos (variedades) para a produção de minimilho (A1 Piratininga, BRS Ângela, Al Bandeirantes, Cativerde 02 e Tropical), em Ituiutaba - MG, e obtiveram maiores valores médios para comprimentos de espiga com palha sendo estes valores entre 23,86 cm e 27,09 cm; os autores também constataram diferença estatística entre os materiais testados para a variável.

As espigas oriundas de plantas despendoadas tiveram comprimento médio de espiga com palha superior em relação aos tratamentos em que não foi realizado o despendoamento, com valor médio de comprimento de espiga com palha de 17,11 cm.

Quanto ao diâmetro médio de espiga com palha (Tabela 4), para as quatro cultivares avaliadas em função do despendoamento, observa-se que a cultivar Pioneer $30 S 40$ diferiu das demais, apresentando valor médio de diâmetro de espiga com palha de 2 cm; as demais cultivares apresentaram médias de diâmetro de espiga com palha de 2,21 cm, 2,20 cm e 2,22 cm para AL 34, BM 3061 e Cativerde 02, respectivamente. Estes valores ficaram próximos dos encontrados por Raup et al. (2008), que obtiveram médias de diâmetro de espiga com palha de 2,31 cm, 2,21 cm, 2,25 cm e 2,21 cm para os híbridos DKB 214, P3021, AG 6018 e DKB 215, respectivamente. A prática do despendoamento não influenciou significativamente nessa variável.

Para os valores médios de Massa de espiga sem palha (Tabela 5) houve interação entre cultivares e tratamentos. Dentro dos tratamentos nos quais permaneceram os pendões nas plantas houve diferença estatística entre cultivares, com a cultivar BM3061 apresentando o maior valor médio de Massa de espiga sem palha, de 8,96 g, sendo este valor 32,54\% superior em relação ao valor médio de Massa de espiga sem palha da cultivar Pioneer 30S40, o qual foi de 6,76 g. As cultivares BM3061 e Pioneer 30S40 foram diferentes entre si em relação ao valor médio de Massa de espiga

Tabela 2 - Valores médios de massa de espiga com palha, em gramas/espiga, de quatro cultivares de milho em função do despendoamento. Marechal Cândido Rondon - PR - 2010

\begin{tabular}{lccc}
\hline \multirow{2}{*}{ Cultivar } & \multicolumn{2}{c}{ Massa de espiga com palha (g) } & \multirow{2}{*}{ Médias } \\
\cline { 2 - 3 } & Com pendão & Sem pendão & $32,27 \mathrm{~A}$ \\
AL 34 & 31,83 & 32,70 & $31,64 \mathrm{~A}$ \\
BM 3061 & 31,55 & 31,73 & $33,98 \mathrm{~A}$ \\
Cativerde 02 & 31,89 & 36,06 & $26,50 \mathrm{~B}$ \\
Pioneer 30S40 & 24,12 & 28,88 & $32,35 \mathrm{~A}$ \\
Médias & $29,85 \mathrm{~B}$ & 32, & \\
\hline
\end{tabular}

* Médias seguidas da mesma letra minúscula, nas linhas, e médias seguidas da mesma letra maiúscula, nas colunas, não diferem entre si pelo teste de Tukey ao nível de 5\%. 
Tabela 3 - Valores médios de comprimento de espiga com palha, em cm, de quatro cultivares de milho em função do despendoamento. Marechal Cândido Rondon - PR - 2010

\begin{tabular}{lccc}
\hline \multirow{2}{*}{ Cultivar } & \multicolumn{2}{c}{ Comprimento de espiga com palha (cm) } & \multirow{2}{*}{ Médias } \\
\cline { 2 - 3 } & Com pendão & Sem pendão & 17,19 A \\
AL 34 & 16,64 & 17,74 & 16,84 A \\
BM 3061 & 16,64 & 17,04 & 17,40 A \\
Cativerde 02 & 16,98 & 17,81 & 15,13 B \\
Pioneer 30S40 & 14,42 & 15,84 & \\
Médias & 16,17 B & 17,11 A & \\
\hline
\end{tabular}

*Médias seguidas da mesma letra minúscula, nas linhas, e médias seguidas da mesma letra maiúscula, nas colunas, não diferem entre si pelo teste de Tukey ao nível de $5 \%$.

Tabela 4 - Valores médios de diâmetro de espiga com palha, em cm, de quatro cultivares de milho em função do despendoamento. Marechal Cândido Rondon - PR - 2010

\begin{tabular}{lccc}
\hline \multirow{2}{*}{ Cultivar } & \multicolumn{2}{c}{ Diâmetro de espiga com palha $(\mathrm{cm})$} & \multirow{2}{*}{ Médias } \\
\cline { 2 - 3 } & Com pendão & Sem pendão & 2,21 A \\
\hline AL 34 & 2,25 & 2,18 & 2,20 A \\
BM 3061 & 2,21 & 2,20 & 2,22 A \\
Cativerde 02 & 2,17 & 2,27 & 2,00 B \\
Pioneer 30S40 & 1,95 & 2,05 & \\
Médias & 2,15 & 2,18 & \\
\hline
\end{tabular}

"Médias seguidas da mesma letra minúscula, nas linhas, e médias seguidas da mesma letra maiúscula, nas colunas, não diferem entre si pelo teste de Tukey ao nível de 5\%.

Tabela 5 - Valores médios de massa de espiga sem palha, em gramas, de quatro cultivares de milho em função do despendoamento. Marechal Cândido Rondon - PR - 2010

\begin{tabular}{lccr}
\hline \multirow{2}{*}{ Cultivar } & \multicolumn{2}{c}{ Massa de espiga sem palha $(\mathrm{g})$} & \multirow{2}{*}{ Médias } \\
\cline { 2 - 3 } & Com pendão & Sem pendão & 7,75 \\
AL 34 & 8,43 AB a & 7,07 A a & 8,53 \\
BM 3061 & 8,96 A a & 8,10 A a & 7,75 \\
Cativerde 02 & 8,21 AB a & 7,28 A a & 7,12 \\
Pioneer 30S40 & 6,76 B a & 7,48 A a & 7,48 \\
Médias & 8,09 & 7,09 & \\
\hline
\end{tabular}

*Médias seguidas da mesma letra minúscula, nas linhas, e médias seguidas da mesma letra maiúscula, nas colunas, não diferem entre si pelo teste de Tukey ao nível de $5 \%$.

sem palha, já as cultivares AL34 e Cativerde 02 apresentaram valores intermediários, não diferindo em relação as demais (BM 3061 e Pioneer 30S40). Raupp et al. (2008) obtiveram valores médios de massa de espiga sem palha maiores, ficando entre $8,7 \mathrm{~g}$ e $10,9 \mathrm{~g}$ nas 4 cultivares que avaliaram. Moreira, Santos e Favarão (2014) avaliaram diferentes genótipos para a produção de minimilho (Milho canjica AL Branco, Milho doce BonaVerde, Milho pipoca Itapuã 900, Milho híbrido simples ATL 200 e Milho super-doce Havaí), obtendo massa média de espiga de 5, 39 g para o híbrido simples ATL 200 e 6,07 g para o milho pipoca Itapuã 900, sendo estes valores estatisticamente iguais entre si, porém diferentes dos demais: 7,25 g para o milho canjica AL Branco, 7,66 g para o milho super-doce Havaí e 8,23 g para o milho doce Bona-Verde. Os valores deste segundo grupo de genótipos ficaram próximos aos apresentados pelas cultivares testadas na presente pesquisa.

Nos tratamentos nos quais foi realizada a retirada dos pendões das plantas não houve diferença estatística 
entre cultivares, também não houve diferença estatística entre os valores médios de Massa de espiga sem palha entre os tratamentos nos quais foi praticado o despendoamento e aqueles nos quais as plantas permaneceram com o pendão.

Na Tabela 6 apresentam-se os valores médios de comprimento de espiga comerciais sem palha. Para esta característica não houve diferença estatística entre tratamentos com despendoamento e plantas com pendão e nem entre cultivares. Os valores apresentados na tabela 6 são menores do que as médias encontradas por Wangen e Faria (2013); estes autores obtiveram valores entre 12,59 cm e 14,01 cm para comprimento de espiga sem palha nos cinco genótipos avaliados, porém também não constataram diferença estatística entre as médias dos genótipos para esta variável.

O valor médio de comprimento de espigas sem palha das cultivares avaliadas foi de 7,69 cm. Em relação aos tratamentos com e sem pendão, o valor médio foi de 7,75 cm para espigas de plantas com pendão, e 7,63 cm para espigas de plantas sem pendão. Estes valores médios de comprimento de espiga sem palha foram maiores do que os encontrados por Pereira Filho et al. (2005), que trabalhando com diferentes níveis de nitrogênio, densidades de semeadura e com e sem pendão não encontraram diferença estatística entre os tratamentos com e sem pendão, sendo que o valor médio encontrado foi de $6,9 \mathrm{~cm}$ para ambos os tratamentos. Estes valores foram menores do que aqueles obtidos por Moreira et al. (2014), que obtiveram valores médios de comprimento de espiga entre $9,16 \mathrm{~cm}$ e 10,38 cm nos 5 genótipos testados; as autoras também não encontram diferença estatística para esta variável. Valores maiores para o comprimento de espiga sem palha também foram obtidos por Lone et al. (2013), que avaliaram a produtividade e lucratividade de minimilho em função de diferentes combinações de doses de adubação orgânica e mineral; os valores médios obtidos ficaram entre 8,71 cm e 10,44 $\mathrm{cm}$, sendo que maiores doses de adubação propiciaram maiores comprimentos de espiga.

Quanto aos valores médios de diâmetro de espiga sem palha (Tabela 7), não ocorreu diferenças entre as médias dos tratamentos com e sem pendão e nem entre as médias das cultivares dentro do tratamento no qual foi feita a remoção dos pendões, porém dentro do tratamento no qual as plantas permaneceram com pendão houve diferença entre as cultivares; portanto ocorreu interação entre cultivares e tratamentos no diâmetro de espiga sem palha. Dentro do tratamento no qual permaneceu o pendão as cultivares AL34 e BM3061 foram superiores em relação a Pioneer 30S40, porém não diferiram da cultivar Cativerde 02, a qual obteve valor intermediário de diâmetro de espiga sem palha, esta também não diferiu em relação a cultivar Pioneer 30S40. As médias de Diâmetro de espiga sem palha das cultivares avaliadas ficaram entre $1,39 \mathrm{~cm}$ e 1,50 $\mathrm{cm}$; estes valores ficaram próximos aos obtidos por Raupp et al. (2008), que avaliando cultivares híbridas para produção de minimilho obtiveram valores médios de Diametro de espigas sem palha entre 1,42 e $1,51 \mathrm{~cm}$. Moreira et al. (2014) obtiveram valor médio de Diâmetro de espiga muito próximo para quatro dos cinco genótipos testado; quatro genótipos não diferiram entre si, apresentando valores médios de Diâmetro de espiga entre $1,37 \mathrm{~cm}$ e 1,42 cm, já o milho pipoca Itapuã 900 diferiu dos demais com valor médio de Diâmetro de espiga de 0,86 cm, sendo este genótipo considerado inferior aos demais para esta variável.

Os valores médios de diâmetro de espiga sem palha foram de 1,46 cm para o tratamento com pendão, e 1,41 $\mathrm{cm}$ para o tratamento sem pendão, valores maiores do que os encontrados por Pereira Filho et al. (2005), que trabalhando com diferentes níveis de nitrogênio, densidades de semeadura e com e sem pendão, não encontraram diferença no diâmetro médio de espiga, obtendo valor médio de $1 \mathrm{~cm}$ tanto para as espigas de plantas com pendão como para as oriundas de plantas sem pendão.

A Tabela 8 apresenta os valores médios de parâmetros de produtividade e rendimento das cultivares avaliadas. Quanto ao número total de espigas (NTESP), as cultivares Pioneer 30540 e BM3061 foram iguais entre si, mas foram superiores em relação as cultivares AL34 e Cativerde 02. A cultivar Pioneer 30 S40 teve número médio de 320.238 espigas ha-1 ${ }^{-1}$ sendo este valor superior ao obtido por Moreira et al. (2010), o qual foi de 254.203 espigas ha ${ }^{1}$ para a cultivar BRS2020. As médias de números de espigas produzidas pelos genótipos testados por Moreira et al. (2014) ficaram entre 56.750 espigas no milho superdoce Havaí e 195.000 espigas no milho híbrido simples ATL 200. Exceto e milho híbrido simples ATL 200, todos os genótipos testados por Moreira, Santos e Favarão (2014) produziram menor quantidade de espigas em relação aos materiais testados na presente pesquisa. 
Tabela 6 - Valores médios de comprimento de espiga sem palha, em cm, de quatro cultivares de milho em função do despendoamento. Marechal Cândido Rondon - PR - 2010

\begin{tabular}{lccc}
\hline \multirow{2}{*}{ Cultivar } & \multicolumn{2}{c}{ Comprimento de espiga sem palha $(\mathrm{cm})$} & \multirow{2}{*}{ Médias } \\
\cline { 2 - 3 } & Com pendão & Sem pendão & 7,50 \\
AL 34 & 7,56 & 7,44 & 7,89 \\
BM 3061 & 7,98 & 7,79 & 7,76 \\
Cativerde 02 & 7,99 & 7,54 & 7,60 \\
Pioneer 30S40 & 7,46 & 7,74 & \\
Médias & 7,75 & 7,63 & \\
\hline
\end{tabular}

${ }^{*}$ Médias seguidas da mesma letra minúscula, nas linhas, e médias seguidas da mesma letra maiúscula, nas colunas, não diferem entre si pelo teste de Tukey ao nível de $5 \%$.

Tabela 7 - Valores médios de diâmetro de espiga sem palha, em cm, de quatro cultivares de milho em função do despendoamento. Marechal Cândido Rondon - PR - 2010

\begin{tabular}{|c|c|c|c|}
\hline \multirow{2}{*}{ Cultivar } & \multicolumn{2}{|c|}{ Diâmetro de espiga sem palha (cm) } & \multirow{2}{*}{ Médias } \\
\hline & Com pendão & Sem pendão & \\
\hline AL 34 & $1,51 \mathrm{Aa}$ & 1,39Аа & 1,45 \\
\hline BM 3061 & 1,53Aa & $1,47 \mathrm{Aa}$ & 1,50 \\
\hline Cativerde 02 & $1,41 \mathrm{ABa}$ & $1,37 \mathrm{Aa}$ & 1,39 \\
\hline Pioneer $30 \mathrm{~S} 40$ & $1,37 \mathrm{Ba}$ & $1,41 \mathrm{Aa}$ & 1,39 \\
\hline Médias & 1,46 & 1,41 & \\
\hline
\end{tabular}

${ }^{*}$ Médias seguidas da mesma letra minúscula, nas linhas, e médias seguidas da mesma letra maiúscula, nas colunas, não diferem entre si pelo teste de Tukey ao nível de 5\%.

Tabela 8 - Valores médios de parâmetros de quatro cultivares de milho em cultivo para minimilho. Marechal Cândido Rondon - PR - 2010

\begin{tabular}{|c|c|c|c|c|c|c|}
\hline Cultivares & NTESP & NCESP & NC/NT & MTCP & MTSP & SP/CP \\
\hline AL 34 & 195238B & 144048B & $0,740 \mathrm{AB}$ & $4652,6 \mathrm{~B}$ & 1099,7B & $0,240 \mathrm{~A}$ \\
\hline BM 3061 & 308333A & 203571 AB & $0,655 \mathrm{~B}$ & $6404,6 \mathrm{AB}$ & $1720,8 \mathrm{~A}$ & $0,272 \mathrm{~A}$ \\
\hline Cativerde 02 & 189286B & 144048B & $0,754 \mathrm{AB}$ & $4854,5 \mathrm{AB}$ & $1120,7 \mathrm{~B}$ & $0,238 \mathrm{~A}$ \\
\hline Pioneer $30 \mathrm{~S} 40$ & 320238A & 266667A & 0,831A & $7086,5 \mathrm{~A}$ & $1902,5 \mathrm{~A}$ & $0,272 \mathrm{~A}$ \\
\hline
\end{tabular}

Número total de espigas (NTESP), em espigas ha ${ }^{-1}$; Número de espigas comerciais (NCESP), em espigas comerciais ha ${ }^{-1}$; relação número de espigas comerciais por número total de espigas (NC/NT); Massa total de espigas comerciais com palha (MTCP), em kg ha-1 Massa $^{-1}$ total de espigas comerciais sem palha (MTCP), em kg ha-1; relação massa de espigas comerciais sem palha por massa de espigas comerciais com palha (SP/CP).

* Médias seguidas da mesma letra maiúscula nas colunas não diferem entre si pelo teste de Tukey ao nível de 5\%.

Para o número de espigas comerciais (NCESP), a cultivar Pioneer 30S40, com produção de 266.667 espigas ha- ${ }^{-1}$, foi superior em relação às cultivares AL34 e Cativerde 02, porém não diferiu da cultivar BM3061, esta última também não diferiu das cultivares AL34 e Cativerde 02. Castro et al. (2013) avaliaram três cultivares de milho (AG 1051, AG 2060 e BRS 2020) para a produção de minimilho, minimilho e posterior colheita de milho verde, e minimilho e posterior colheita de milho em grão, e constatam que a cultivar BRS 2020 mostra-se superior quando destinada para produção exclusiva de minimilho, com produção de 92.145 espigas comerciais ha-1 ${ }^{-1}$, valor este inferior aos obtidos na presente pesquisa.

A cultivar BM3061 apresentou a menor relação de número de espigas comerciais por número total de espigas (NC/NT), sendo que esta relação foi de 0,65, estatisticamente inferior a cultivar Pioneer 30S40, que teve relação de 0,831 . As demais cultivares (AL34 e Cativerde 02) apresentaram valores intermediários e não diferiram das cultivares BM3061 e Pioneer $30 S 40$. 
Para os valores médios de Massa total de espigas comerciais com palha (MTCP), conforme Tabela 8, houve diferença entre as cultivares; a Pioneer 30540 foi superior a cultivar AL34, porém não diferiu das demais, sendo que para a AL34 a produtividade de Massa total de espigas comerciais com palha foi de 4.652,6 $\mathrm{kg} \mathrm{ha}^{-1}$ e para a Pioneer $30 \mathrm{~S} 40$ a produtividade de espigas comerciais com palha foi de $7.086,5 \mathrm{~kg} \mathrm{ha}^{-1}$, havendo portanto, uma diferença de $2.433,9 \mathrm{~kg} \mathrm{ha}^{-1}$ entre estas cultivares, o que representa 52,31\% a mais para Pioneer 30 S40 em relação a AL34.

A Massa total de espigas comerciais foi de 1.902,5 $\mathrm{kg} \mathrm{ha}^{-1}$ para a cultivar Pioneer 30S40, 73\% maior do que o valor obtido pela cultivar AL34, a qual teve a menor produtividade, $1.099,7 \mathrm{~kg} \mathrm{ha}^{-1}$. Os genótipos testados por Wangen \& Faria (2013) não diferiram entre si, apresentado valores médios de produtividade de espigas (minimilho) entre 759,60 kg ha-1 e 1.172,0 kg $\mathrm{ha}^{-1}$. Lone et al. (2013) obtiveram Massa total de espigas comerciais entre $1.601 \mathrm{~kg} \mathrm{ha}^{-1}$ e $2060 \mathrm{~kg} \mathrm{ha}^{-1}$, sendo esta variação devida a diferentes combinações de doses de adubação orgânica e mineral.

A Tabela 8 também apresenta a relação entre a Massa total de espigas comerciais sem palha e Massa total de espigas comerciais com palha (SP/CP). Os valores variaram entre 0,238 e 0,272, porém não houve diferença estatística entre as cultivares avaliadas para esta característica. Esses valores ficaram próximos dos valores encontrados por Raup et al. (2008), que avaliando 4 híbridos para a produção minimilho obtiveram rendimentos de 24,59\%, 27,53\%, 20,40\% e 23,70\% em massa média de minimilho sem palha em relação à matériaprima com palha para os híbridos DKB 214, P3021, AG 6018 e DKB 21, respectivamente.

Os valores médios dos parâmetros de produtividade e rendimento dos tratamentos com e sem a realização do despendoamento são apresentados na Tabela 9. O despendoamento das plantas proporcionou aumento do número total de espigas (NTESP), havendo uma diferença de 18,2 \% no número total de espigas produzidas ha-1 com a prática do despendoamento, produzindo-se em média 274.405 espigas ha-1 no tratamento no qual houve remoção do pendão. Moreira et. al. (2010) obtiveram produção de 267.751 espigas ha $^{-1}$ para plantas sem pendão e 236.726 espigas ha${ }^{1}$ para os tratamentos nos quais as plantas de milho que permaneceram com pendão.
Para o número de espigas comerciais não houve diferença estatística entre os tratamentos. Os valores foram de 202.976 espigas comerciais ha ${ }^{-1}$ para o tratamento sem pendão e 176.190 espigas comerciais ha ${ }^{-1}$ para os tratamentos nos quais as plantas permaneceram com o pendão. Moreira et al. (2010) obtiveram valor superior de espigas comercias, sendo de 233.861 espigas comerciais sem casca ha-1 para o tratamento com despendoamento e 210.185 espigas comercias descascadas ha ${ }^{-1}$ para o tratamento sem despendoamento; para Moreira et. al. (2010) também não houve diferença estatística para esta variável.

Não houve diferença estatística na relação do número de espigas comerciais por número total de espigas (NC/NT).

A Tabela 9 também apresenta os valores médios de Massa total de espigas comerciais com palha (MTCP), Massa total de espigas comerciais sem palha (MTCP) e a relação entre massa de espigas comerciais sem palha e massa de espigas comerciais com palha (SP/CP) em função da realização ou não do despendoamento.

Houve diferença estatística entre os tratamentos para a Massa total de espigas comerciais com palha, sendo que para o tratamento com pendão a produtividade foi de $5.087,5 \mathrm{~kg} \mathrm{ha}^{-1}$, e para os tratamentos nos quais foi realizada a remoção do pendão a Massa total de espigas comerciais com palha foi de $6.411,6 \mathrm{~kg} \mathrm{ha}^{-1}$, o que representa uma diferença de $1.324,1 \mathrm{~kg} \mathrm{ha}^{-1}$ entre os tratamentos.

Não ocorreu diferença estatística para Massa total de espigas comerciais sem palha, sendo os valores médios de 1392,7 e 1529,2 kg ha-1 para os tratamentos com pendão e sem pendão, respectivamente. Moreira et al. (2010) obtiveram 2.138 e $1.908 \mathrm{~kg} \mathrm{ha}^{-1}$, respectivamente para os tratamentos com e sem despendoamento, também não havendo diferença estatística entre estes valores.

Para a relação entre Massa de espigas comerciais sem palha e Massa de espigas comerciais com palha (SP/CP) houve diferença estatística entre os tratamentos com e sem a prática do despendoamento (parâmetro este chamado de rendimento comercial por Pereira Filho et al. (2005)), sendo que no tratamento no qual não houve remoção do pendão a relação citada acima foi 0,273, valor este estatisticamente superior a 0,237 obtidos nos tratamentos nos quais realizou-se o despendoamento das plantas, ou seja, o despendoamento influenciou 
Tabela 9 - Valores médios de parâmetros de despendoamento em cultivo de minimilho. Marechal Cândido Rondon. 2010

\begin{tabular}{lcccccc}
\hline Tratamentos & NTESP & NCESP & NC/NT & MTCP & MTSP & SP/CP \\
\hline Sem despendoamento & 232143B & 176190A & 0,758A & 5087,5B & 1392,7A & 0,273A \\
Com despendoamento & 274405A & 202976A & 0,733A & 6411,6A & 1529,2A & 0,237B \\
\hline
\end{tabular}

Número total de espigas (NTESP), em espigas ha ${ }^{-1}$; Número de espigas comerciais (NCESP), em espigas ha' ${ }^{-1}$; relação entre número de espigas comerciais e número total de espigas (NC/NT); Massa total de espigas comerciais com palha (MTCP), em kg ha-1; Massa total de espigas comerciais sem palha (MTCP), em kg ha ${ }^{-1}$; relação entre Massa de espigas comerciais sem palha e Massa de espigas comerciais com palha (SP/CP).

"Médias seguidas da mesma letra maiúscula nas colunas não diferem entre si pelo teste de Tukey ao nível de 5\%.

mais no ganho de massa de palha nas espigas; em porcentagem estes valores equivalem a 27,3 e 23,7\%, respectivamente. Pereira Filho et al. (2005) também constataram diferença de rendimento em experimento realizado em Sete Lagoas-MG, sendo de 29,5\% para as espigas de plantas com pendão e 27,5 \% para as espigas de plantas despendoadas.

Resultado diferente foi encontrado por Pereira Filho et al. (2009), que avaliaram seis cultivares de milho em três épocas, visando à produção de minimilho no Estado de Minas Gerais, e observaram que as cultivares apresentaram melhores rendimentos comerciais na ausência do pendão, com médias de rendimento de $18,37 \%$ para os tratamentos com plantas com pendão e $19,72 \%$ para as despendoadas.

\section{CONCLUSÃO}

As cultivares possuem diferentes potencialidades de produção de minimilho, diferindo tanto na produtividade quanto em características de qualidade, principalmente as que se referem as dimensões das espigas formadas.

As cultivares Pioneer 30S40 e BM3061 mostraramse mais produtivas no número total de espigas e na produtividade de Massa de espigas comerciais sem palha, e pelos níveis de produtividades alcançados são promissoras para serem utilizadas na produção de minimilho.

O despendoamento proporciona o aumento no número de espigas totais, mas não afetou o número de espigas comerciais produzidas.

O despendoamento afeta mais a produção de espigas com palha, porém não proporciona ganho na massa de espigas sem palha, portanto não é uma prática recomendada, tendo em vista que representa aumento de custos de produção.

\section{LITERATURACITADA}

ALMEIDA, I.P.C.; SILVA, P.S.L.; NEGREIROS, M.Z. et al. Baby corn, green ear, and grain yield of corn cultivars. Horticultura Brasileira, v.23, n.4, p.960-964, 2005. In: http://www.scielo.br/ pdf/\%0D/hb/v23n4/a20v23n4.pdf (acessado em 26 de outubro de 2017).

ARCANJO JUNIOR, H.G.; NASCIMENTO, W.G.; MACEDO, I.M. et al. Características químicas bromatológicas de plantas remanescentes a cultura do minimilho. Revista Brasileira de Saúde e Produção Animal, v.17, n.3, p.344-354, 2016. In: http://revistas.bvs-vet.org.br/ rbspa/article/view/35075/39413 (acessado em 25 de outubro de 2017).

CASTRO, R.S.; SILVA, P.S.L.; CARDOSO, M.J. Baby corn, green corn, and dry corn yield of corn cultivars. Horticulura Brasileira, v.31, n.1, 2013. In: http://www.scielo.br/pdf/hb/v31n1/ v31n1a16.pdf (acessado em 31 de outubro de 2017).

LIMA, A.S.O.D.; MELO, A.R.; OLIVEIRA, L.F. et al. Análises físicas, composição centesimal e nutricional de minimilho (Zea mays, L.) orgânico de diferentes variedades. Revista Verde, v.10, n.5 (Especial), p.49-55, 2015. In: http://oaji.net/ articles/2016/2238-1460574574.pdf (acessado em 26 de outubro de 2017).

LONE, A.A.; ALLAI, B.A.; NEHVI, F.A. Growth, yield and economics of baby corn (Zea mays L.) as influenced by Integrated Nutrient Management (INM) practices. African Journal of Agricultural Research, v.8, n.37, p.45374540, 2013. In: http://www.academicjournals.org/ journal/AJAR/article-full-text-pdf/C8F3F9737922 (acessado em 30 de outubro de 2017). 
MELO, A.R.; LIMA, A.S.O.D.; OLIVEIRA, L.F. et al. Conservas de minimilho (Zea mays, $L$.) orgânico: Processamento e aceitação sensorial. Revista Verde, v.9, n.4, p.271-277, 2014. In: http:// www.gvaa.com.br/revista/index.php/RVADS/article/ view/2649 (acessado em 26 de outubro de 2017).

MOREIRA, J.N.; SILVA, P.S.L.; SILVA, K.M.B. et al. Effect of detasseling on baby corn, green ear and grain yield of two maize hybrids.

Horticultura Brasileira, n.28, p.406-411, 2010. In: http://www.scielo.br/pdf/hb/v28n4/05.pdf (acessado em 29 de outubro de 2017).

MOREIRA, A.; SANTOS, M.Z.; FAVARÃO, S.C.M. Características agronômicas de genótipos de milho para a produção de minimilho. Revista em Agronegócios e Meio Ambiente, v.7, n.3, p.633-643, 2014. In: http:// periodicos.unicesumar.edu.br/index.php/rama/ article/viewFile/2889/2404 (acessado em 30 de outubro de 2017).

PEREIRA FILHO, I.A.; CRUZ, J.C.; QUEIROZ, V.A.V. et al. Avaliação de cultivares de milho visando à produção de minimilho na Região Norte do estado de Minas Gerais. Empresa Brasileira de Pesquisa Agropecuária - Centro Nacional de Pesquisa de Milho e Sorgo, 2009. 5p. (EMBRAPA - CNPMS. Circular Técnica, 131). In: https://ainfo.cnptia.embrapa.br/ digital/bitstream/CNPMS-2010/22396/1/Circ-131.pdf (acessado em 29 de outubro de 2017).
PEREIRA FILHO, I.A.; CRUZ, J.C.; ALVARENGA, R.C. Efeito de densidade de semeadura, níveis de nitrogênio e despendoamento sobre a produção de minimilho. Empresa Brasileira de Pesquisa Agropecuária, 2005. 4p. (Comunicado Técnico 119). In: https://ainfo.cnptia.embrapa.br/digital/ bitstream/CNPMS/18434/1/Com_119.pdf (acessado em 31 de outubro de 2017).

RAUPP, D.S.; GARDINGO, J.R.; MORENO, L.R. et al. Minimilho em conserva: avaliação de híbridos. Acta Amazônica, v.38, n.3, p.509-516, 2008. In: http://www.scielo.br/pdf/aa/v38n3/ v38n3a16.pdf (acessado em 29 de outubro de 2017).

SILVA, P.S.L.; SILVA, P.I.B.; SOUSA, A.K.F. et al. Green ear yield and grain yield of maize after harvest of the first ear as baby corn.

Horticultura Brasileira, v.24, n.2, p.151155, 2006. In: http://www.scielo.br/pdf/hb/v24n2/ 05.pdf (acessado em 30 de outubro de 2017).

WANGEN, D.R.B.; FARIA, I.O. Avaliação de variedades de milho para produção de minimilho. Enciclopédia Biosfera, Centro Científico Conhecer, v.9, n.17, p.385-392, 2013. In: http:// www.conhecer.org.br/enciclop/2013b/ CIENCIAS\%20AGRARIAS/

Avaliacao\%20de\%20variedades.pdf (acessado em 26 de outubro de 2017).

Recebido para publicação em 10/4/2017 e aprovado em 31/10/2017. 